\title{
NEGATIVE TRENDS IN OUTPATIENT CARE OF ADDICTED PATIENTS IN HUNGARY
}

\author{
Miklós Péter Kalapos \\ Theoretical Biology Research Group, Budapest, Hungary
}

\begin{abstract}
SUMMARY
Objectives: This article investigates how the numbers of registered addict patients have changed in the last three decades in Hungary and whether the predicted HIV epidemic among intravenous drug users has occurred.

Methods: Data were collected from the Annual Reports of the National Bureau of Statistics and National Epidemiological Centre as well as from the medical records of the author.

Results: The total number of registered alcoholics decreased by about $75 \%$ during the investigated period. This decrease was more pronounced among males than females. After initial increase, the number of registered drug addicts showed stagnation with an about 50\% drop-out rate. Fortunately, the anticipated HIV epidemic did not manifest. The negative effect of a poor political action upon the number of client visits could, however, be documented.

Conclusion: In conclusion, negative trends are seen in the Hungarian addiction care. Numerous variables may be taken into consideration as affecting factors, but it is not yet clear to what extent these negative factors are responsible for trends. These data, however, warrant further investigations.
\end{abstract}

Key words: alcoholic, drug addict, Jellinek formula, HIV infection, outpatient clinic

Address for correspondence: M. P. Kalapos, Theoretical Biology Research Group, H-1029 Budapest, Dámvad utca 18., Budapest, Hungary. E-mail: MPKalapos@Freemail.Hu

https://doi.org/10.21101/cejph.a5419

\section{INTRODUCTION}

Consuming psychoactive substances, whether legal (alcohol, medicines, smoking, caffeine) or illegal (drugs), and dependence on those are serious worldwide problem $(1,2)$. Hungary is not an exception from this general rule (3).

The only difference in the use of psychoactive chemical substances among countries is which compound is preferred. This may change from country to country depending on several factors. In Hungary, all the above listed groups of psychoactive chemical substances are available. Addiction places a heavy burden not only on the public health system in terms of prevention, treatment and care of chemical substance abusers, but also has a strong influence on other areas of society (criminality, working, taxation), too.

At the end of the 1970s the then reigning Hungarian government recognized the seriousness of the problem of alcoholism and the result was a change in government policy (4). The two main components of government policy were the organization of outpatient care system for addicted clients and the compulsory treatment of alcoholics. Since the political atmosphere drastically changed in 1989, the government policy changed again partly due to the fact that illegal chemicals including their intravenous use appeared in the country. The political restructuring was accompanied with reduction in psychiatric bed capacities as a sign of a uniform political paradigm for the region (5). However, forensic psychiatric capacities were extended in the majority of Eastern European countries (5).
Epidemiologic data show a coexistence of HIV infection and intravenous drug use, particularly in those countries in which needle exchange programmes (NEP) meet difficulties (6-8). According to the Hungarian statistical records, the total number of HIV infected patients has increased in the last 25 years, from 216 in the year 1990 to 2,747 in the year 2015, but the new cases were almost exclusively due to homosexual relationships (National Epidemiologic Centre). Nevertheless, certain Hungarian authors emphasize the risk of an HIV outbreak among intravenous drug users (IDU) similarly to the experiences in Greece (7-10).

The basic aim of the article was to examine the changes of the number of registered addicted patients in Hungary in order to gain insight into the trends of the last thirty years. In addition, data are shown that question the high risk of an HIV outbreak predicted by other authors. Moreover, a case study is presented on the impact of a politically motivated intervention in an outpatient care facility.

\section{MATERIALS AND METHODS}

The following sources of data were used: the Annual Reports of the National Bureau of Statistics (Budapest, Hungary) released between the years 1990 and 2017 were used to provide items upon alcoholics and drug abusers. Data on the nationwide HIV/AIDS infection between 1986 and 2017 were taken from the report of National Epidemiological Centre (Budapest, Hungary) as well as 
from the STADAT 2.4.4. Report "Blood supply, ambulance service, people living with HIV and AIDS patients (1990)" released by the National Bureau of Statistics (Budapest, Hungary). HIV/ AIDS data for individuals originated either from the author's own medical record or from organizations established for the care of illicit drug users and work in 8th District of Budapest.

Data of monthly as well as yearly changes in the number of new patients, and the total number of visits on yearly basis were collected between January 2013 and December 2017 in the author's office (Outpatient Clinic for Addictology, 8th District of Budapest, Hungary). It is to be noted that the Outpatient Clinic for Addictology belongs to a health care supplier maintained by the District municipality. For percentage calculation, rounding to the second decimal place was used.

\section{RESULTS}

\section{Number of Registered Alcoholics and Drug Addicts on National Basis}

The changes of the number of registered alcoholics in Hungary in the last 28 years are presented in Table 1. As seen, during the almost three decades after the political change in Hungary, the total number of registered alcoholics decreased by a bit more than $75 \%$. At the same time, the male to female ratio has also been altered. Taking the 1989 data as $100 \%$, the number of registered female and male patients in 2017 was $29.21 \%$ and $18.64 \%$, respectively, of the baseline. Over the years the estimated number of alcoholics has strongly fluctuated which in fact mirrors the fluctuation of data regarding the changes in the number of alcoholic liver disease

Table 1. Number of registered alcoholics, estimated number of alcoholics and number of alcoholic liver disease deaths between 1989 and 2017 in Hungary

\begin{tabular}{|c|c|c|c|c|c|c|}
\hline \multirow{2}{*}{ Year } & \multicolumn{3}{|c|}{ Registered patients treated with alcohol problems } & \multirow{2}{*}{$\begin{array}{c}\text { Registered patients treated } \\
\text { with alcohol problems per } \\
100,000 \text { citizens (1989 data) } \\
\text { n (\%) }\end{array}$} & \multirow{2}{*}{$\begin{array}{l}\text { Estimated number } \\
\text { of alcoholics }\end{array}$} & \multirow{2}{*}{$\begin{array}{c}\text { Number } \\
\text { of alcoholic liver } \\
\text { disease deaths }\end{array}$} \\
\hline & Men & Women & Total & & & \\
\hline 1989 & 57,669 & 13,326 & 70,995 & $681(100.00)$ & 590,000 & 4,100 \\
\hline 1990 & 53,070 & 11,346 & 64,416 & $621(91.19)$ & 587,520 & 4,080 \\
\hline 1991 & 48,853 & 10,719 & 59,572 & $574(84.29)$ & 611,000 & 4,246 \\
\hline 1992 & 44,984 & 10,483 & 55,467 & $535(78.56)$ & 836,000 & 5,805 \\
\hline 1993 & 43,095 & 10,215 & 53,310 & $514(75.48)$ & 995,000 & 6,908 \\
\hline 1994 & 41,836 & 10,818 & 52,654 & $509(74.74)$ & $1,048,000$ & 7,277 \\
\hline 1995 & 43,139 & 11,584 & 54,723 & $529(77.68)$ & $1,051,776$ & 7,304 \\
\hline $1996^{a}$ & 40,597 & 11,426 & 52,026 & $504(74.01)$ & 794,000 & 5,515 \\
\hline 1997 & 38,349 & 10,746 & 49,095 & $483(70.93)$ & 808,000 & 5,612 \\
\hline 1998 & 38,568 & 11,405 & 49,973 & 493 (72.39) & 860,000 & 5,972 \\
\hline 1999 & 36,403 & 10,840 & 47,243 & $468(68.72)$ & 866,000 & 6,016 \\
\hline 2000 & 32,326 & 9,946 & 42,272 & $414(60.79)$ & 829,008 & 5,757 \\
\hline 2001 & 30,318 & 9,046 & 39,364 & $387(56.83)$ & 755,000 & 5,245 \\
\hline 2002 & 25,943 & 8,351 & 34,300 & $338(49.63)$ & 717,840 & 4,985 \\
\hline 2003 & 25,607 & 8,268 & 33,875 & $334(49.05)$ & 717,984 & 4,986 \\
\hline 2004 & 24,340 & 8,879 & 33,219 & $311(45.67)$ & 692,000 & 4,808 \\
\hline 2005 & 24,470 & 8,418 & 32,888 & $326(47.87)$ & 432,000 & 3,000 \\
\hline 2006 & 21,682 & 7,340 & 29,022 & 288 (42.29) & 509,000 & 3,538 \\
\hline 2007 & 18,778 & 7,262 & 26,040 & $259(38.03)$ & 490,000 & 3,405 \\
\hline 2008 & 14,301 & 5,670 & 20,152 & $201(29.52)$ & 539,000 & 3,741 \\
\hline 2009 & 11,178 & 3,893 & 15,071 & $150(22.03)$ & 559,000 & 3,885 \\
\hline 2010 & 13,772 & 4,856 & 18,984 & $190(27.90)$ & 522,000 & 3,625 \\
\hline 2011 & 11,675 & 3,907 & 16,035 & $161(23.64)$ & 475,000 & 3,297 \\
\hline 2012 & 8,108 & 3,277 & 11,385 & $115(16.87)$ & 434,000 & 3,015 \\
\hline 2013 & 8,651 & 3,762 & 12,413 & $126(18.50)$ & 390,000 & 2,705 \\
\hline 2014 & 11,188 & 3,556 & 14,744 & $150(22.03)$ & 408,000 & 2,836 \\
\hline 2015 & 11,329 & 4,354 & 15,683 & $160(23.49)$ & 393,000 & 2,731 \\
\hline 2016 & 12,952 & 5,033 & 17,985 & $180(26.43)$ & 375,000 & $\mathrm{NDA}^{\mathrm{c}}$ \\
\hline 2017 & 10,753 & 3,893 & $15,292^{b}$ & $160(23.49)$ & 379,000 & NDA \\
\hline
\end{tabular}

a ince this year the revised version of ICD-10 has been used.

${ }^{\mathrm{b}}$ The difference is due to the fact that in some cases the gender of clients was not recorded.

cNDA - no data available in the annual report 
deaths. This fact indicates that the method, Jellinek formula, is not the most appropriate way to get a real measure of the problem.

Table 2 displays data on the number of registered drug addicts. Until 2006 a continuous increase is seen in the number of registered drug addicts followed by stagnation for a six-year period and finally a slight decrease is observable. Both the total number and the gender distribution of registered clients feature variability without a clear tendency. This variability is also typical for the case of drug users appearing in treatment for the first time. Nonetheless, it is interesting to note that about $40-50 \%$ of annually registered drug addicts are those appearing for the first time indicating that about $40-50 \%$ of clients disappear from the system.

\section{Effect of Political Action on Appearance of New Clients in Addictology Clinic}

The Outpatient Clinic for Addictology, where the author was employed, is situated in the 8th District of Budapest, where BluePoint, the largest civil organization devoted to NEP in Budapest, operated until finishing its operation. The reason for giving up their service in the District was that Blue Point was blamed by the mayor of the District for the local drug problem for couple of years (9). It was a political assumption that NEP was responsible for used syringes in the streets and playgrounds (9). The turning point in political pressure was in January 2014, when the local consultative forum for drug problems excluded Blue Point from the plenum. This action was highly publicized at that time. Finally, the NEP rapidly closed in August 2014 and the Blue Point stopped its operation in the 8th District soon enough (9). After such a history, it was interesting to investigate whether these changes had any influence on the operation of outpatient clinic. The change in the number of new clients was chosen as an indicator.

As shown in Figure 1 (panel A), the monthly number of new clients, even though the fluctuation remained characteristic for enrolment, started decreasing after this affair became known. The decline became more pronounced after NEP shut down (Fig. 1, panel A). The annual number of registered new clients clearly shows a substantial fall in two consecutive years, but finally got

Table 2. Number of registered drug users, number of drug users appeared in treatment for the first time and number of drug users disappeared from the system between 1990 and 2017 in Hungary

\begin{tabular}{|c|c|c|c|c|c|}
\hline \multirow{2}{*}{ Year } & \multicolumn{3}{|c|}{ Registered patients treated with drug problems ${ }^{a}$} & \multirow{2}{*}{$\begin{array}{l}\text { Number of drug users } \\
\text { appeared in treatment } \\
\text { for the first time }\end{array}$} & \multirow{2}{*}{$\begin{array}{c}\text { Number of drug users } \\
\text { disappeared from the } \\
\text { system }^{\mathrm{b}}\end{array}$} \\
\hline & Men & Women & Total & & \\
\hline 1990 & $\mathrm{NDA}^{\mathrm{c}}$ & NDA & NDA & NDA & NDA \\
\hline 1996 & NDA & NDA & NDA & NDA & NDA \\
\hline 1997 & 5,729 & 2,765 & 8,484 & 4,368 & $N C^{d}$ \\
\hline 1998 & 6,459 & 2,999 & 9,458 & 5,275 & 4,301 \\
\hline 1999 & 8,032 & 4,733 & 12,765 & 5,770 & 2,463 \\
\hline 2000 & 8,784 & 4,005 & 12,789 & 4,701 & 5,377 \\
\hline 2001 & 8,356 & 3,693 & 12,049 & 4,342 & 5,082 \\
\hline 2002 & 7,544 & 5,233 & 12,777 & 4,717 & 3,989 \\
\hline 2003 & 9,267 & 5,726 & 14,993 & 5,958 & 3,802 \\
\hline 2004 & 9,477 & 4,688 & 14,165 & 5,655 & 6,423 \\
\hline 2005 & 9,931 & 4,862 & 14,793 & 6,319 & 5,691 \\
\hline 2006 & 10,477 & 5,003 & 15,480 & 5,673 & 4,986 \\
\hline 2007 & 8,942 & 4,655 & 13,597 & 4,050 & 5,933 \\
\hline 2008 & 9,264 & 5,089 & 14,353 & 4,635 & 3,879 \\
\hline 2009 & 7,966 & 5,144 & 13,140 & 3,802 & 5,015 \\
\hline 2010 & 9,854 & 7,069 & 16,923 & 5,337 & 2,554 \\
\hline 2011 & 10,858 & 5,292 & 16,150 & 5,781 & 6,534 \\
\hline 2012 & 9,662 & 6,354 & 16,016 & 5,883 & 6,017 \\
\hline 2013 & 7,906 & 4,208 & 12,114 & 4,864 & 8,766 \\
\hline 2014 & 9,878 & 4,390 & 14,268 & 6,866 & 4,712 \\
\hline 2015 & 8,833 & 3,517 & 12,350 & 5,566 & 7,484 \\
\hline 2016 & 9,357 & 4,235 & 13,592 & 3,988 & 2,746 \\
\hline 2017 & NDA & NDA & NDA & NDA & $\mathrm{NC}$ \\
\hline
\end{tabular}

${ }^{a}$ Data between 1991 and 1995 were not available in the source of information.

${ }^{b}$ The number of drug users disappeared from the system was calculated by the following equation: $\mathrm{Di}=\mathrm{Hi}-1+\mathrm{Ni}-\mathrm{Hi}$, where $\mathrm{Di}-\mathrm{drug}$ users disappeared from the system in the given year, $\mathrm{Hi}-1$ - drug users in the year preceding the year investigated, $\mathrm{Ni}$ - drug users appearing for the first time in the given year, $\mathrm{Hi}$ - registered drug users in the given year.

'NDA - no data available since data were not collected in this regard in 1996 and in previous years.

${ }^{\mathrm{d}} \mathrm{NC}-$ not possible to calculate 
attenuated (Fig. 1, panel B). With some delay in time, the total number of patient visits also decreased, but remained relatively moderate with an about $20 \%$ reduction of visits and thus stabilized at a lower level (Fig. 1, panel C).

\section{HIV Cases on National Basis and in 8th District of Budapest}

The profile of newly diagnosed cases of HIV positive drug abusing clients is displayed in Table 3 .

Detailed national dataset on the number of HIV infections, AIDS disease and deaths due to this infection is shown in Table 4.

\section{DISCUSSION}

In the Hungarian healthcare system the outpatient clinics for addict clients are alcohol and drug addiction treatment centres for males and females funded by the National Health Insurance Fund. Recruitment eligibility is at least 18 years of age. These clinics are devoted to the treatment of acute episodes of these disorders (intoxication, withdrawal) when residential treatment of clients is not needed, and also to long-term treatment, termed tending. Tending is a process, which offers a continuous monitoring, control,

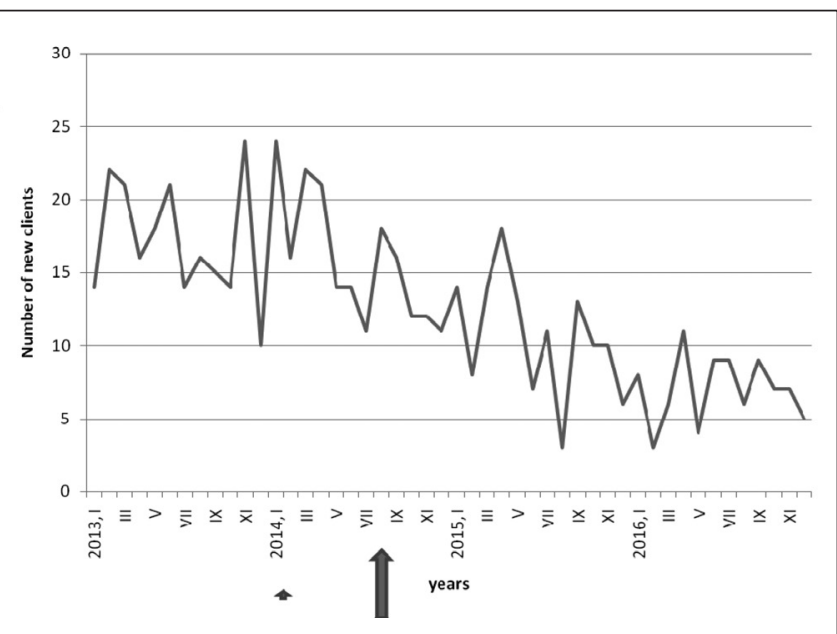

Fig. 1. (panel A). Number of new clients in outpatient clinic upon monthly (panel A) and annual basis (panel B), and total number of client visits in given years (panel $C$ ).

The small arrow and the large arrow indicate the time-point when disclosure affair became known and when Blue Point stopped its operation in the 8th district of Budapest, respectively.
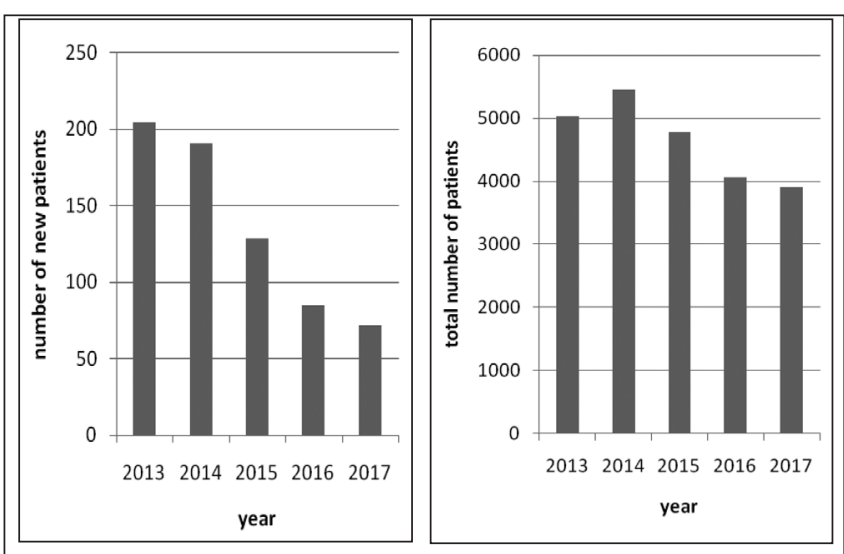

Fig. 1. (panel B, panel C). Number of new clients in outpatient clinic upon monthly (panel $A$ ) and annual basis (panel B), and total number of client visits in given years (panel C).

treatment for the patients in addition to preventing the worsening of their medical status as well as reducing their complaints (11). According to Hungarian statistics, registered addicted clients are those who are patients in any of the above-mentioned alcohol and drug addiction treatment centres (Tables 1 and 2). In these centres abstinence and long-term recovery from addiction are expected, and each patient receives the best possible care.

In this article, the changes of the numbers of registered addicted patients are analysed. As seen, the number of registered alcoholics drastically decreased, while the number of registered drug abusing clients after an increase rather showed stagnation. The drop-out rate was, however, remarkable (Tables 1 and 2). The changes of this kind depend on several possible factors including political, legal and socioeconomic traits, changed very fast within a historically short period of time, thus shocking society. Numerous variables may be taken into consideration as having influenced how individuals reacted to social changes, with particular emphasis on the previously unknown unemployment in Hungarian society. People encountered a new political system in which they had difficulties coping with new changes. These changes were accompanied with the increased availability of until then unknown illegal drugs and resulted in the rise of the number of illicit drug users (Table 2). At this time, homelessness also appeared in Hungary at a substantial rate. Homeless people more frequently suffer from chronic psychiatric disorders and/or are addicted to legal or illicit chemical substances more than other members of the society $(12,13)$. Those people who still had jobs worked more than ever before leading to exhaustion. As a result, they had no time to visit medical services.

Table 3. Summary of HIV positive intravenous drug users in 8th District of Budapest in investigated period

\begin{tabular}{|l|l|c|c|c|}
\hline $\begin{array}{l}\text { Age of client at the time } \\
\text { of infection verification }\end{array}$ & Medical record & $\begin{array}{c}\text { Is the client under } \\
\text { treatment? }\end{array}$ & $\begin{array}{c}\text { Prostitution } \\
\text { in record }\end{array}$ & Homo-sexuality \\
\hline $31(2014)$ & $\begin{array}{l}\text { Intravenous drug use did not share needle, but stored } \\
\text { together with that of others identified by street workers }\end{array}$ & No & Yes & NDA \\
\hline $42(2015)$ & Identified during NEP & No & NDA & NDA \\
\hline $40(2016)$ & Identified during NEP porn actor & No & Yes & NDA \\
\hline $32(2016)$ & Identified in hospital & Yes & NDA & Denied \\
\hline $37(2016)$ & Identified during NEP intravenous drug use for 10 years & No & NDA & NDA \\
\hline
\end{tabular}

NEP - needle exchange programme; NDA - no data available 
Table 4. Number of new HIVIAIDS cases and AIDS related deaths

\begin{tabular}{|c|c|c|c|}
\hline \multirow{2}{*}{ Year } & \multicolumn{2}{|c|}{ Newly registered cases } & \multirow{2}{*}{ Death } \\
\hline & HIV & AIDS & \\
\hline 1989 & 36 & 15 & 10 \\
\hline 1990 & 40 & 19 & 7 \\
\hline 1991 & 55 & 30 & 18 \\
\hline 1992 & 62 & 33 & 16 \\
\hline 1993 & 56 & 32 & 24 \\
\hline 1994 & 65 & 23 & 34 \\
\hline 1995 & 81 & 31 & 13 \\
\hline 1996 & 62 & 46 & 25 \\
\hline 1997 & 72 & 31 & 25 \\
\hline 1998 & 74 & 36 & 20 \\
\hline 1999 & 62 & 37 & 11 \\
\hline 2000 & 48 & 27 & 15 \\
\hline 2001 & 83 & 20 & 8 \\
\hline 2002 & 78 & 26 & 10 \\
\hline 2003 & 63 & 26 & 10 \\
\hline 2004 & 75 & 23 & 13 \\
\hline 2005 & 80 & 33 & 6 \\
\hline 2006 & 106 & 22 & 6 \\
\hline 2007 & 81 & 23 & 10 \\
\hline 2008 & 145 & 23 & 4 \\
\hline 2009 & 140 & 23 & 9 \\
\hline 2010 & 182 & 28 & 10 \\
\hline 2011 & 162 & 32 & 12 \\
\hline 2012 & 219 & 48 & 9 \\
\hline 2013 & 240 & 42 & 7 \\
\hline 2014 & 271 & 51 & 15 \\
\hline 2015 & 271 & 43 & 11 \\
\hline 2016 & 228 & 53 & 10 \\
\hline 2017 & 223 & 52 & 8 \\
\hline
\end{tabular}

This may explain reasons for the change in alcohol consumption in the population (Table 1).

The social changes themselves do not give sufficient explanation for the events, therefore, the role of healthcare system also needs to be evaluated. The fundamental segments of tending in addictology are whom, how, where, and how long to take care (11). Whatever methods are used to treat addicted patients they are more beneficial to the society than the no intervention attitude that neglects the problem (14). Addictology has lost lot of its influence in Hungary due to the decreased funding, shortage of professionals and closure of inpatient wards. Concurrently, it has been unable to adapt itself to new conditions. Also in play has been a continuously changing political will riding on population's fears of addicted people eventually leading to ever changing rules (11).

The availability of treatment is an important factor in determining how an addict patient or a person in trouble can receive support in need. It is a complex idea involving such dimensions as accessibility, effectiveness, appropriateness, efficiency, continuity, privacy, confidentiality, participation, safety, and supportiveness (15). Undoubtedly, both financing and reimbursement have a critical influence on the future of addiction treatment services. The under-funding of facilities affects treatment availability. These policy tools are in the hands of the decision-makers who exploit the public's fear of addicts (16-19). Hungarian statistical data covering the period from 2003 to 2017 point to the withdrawal of funds and GDP ratio of healthcare expenditures has decreased from $8.1 \%$ to $6.7 \%$. As financing declines, a critical point is reached where the system disintegrates. Perhaps, these trends already reflect the signs of disintegration.

The negative effects of a poor political decision are shown in Figure 1. As seen, the closure of NEP in a District of Budapest led, after the lag period, to the decrease of client visits in the municipal outpatient clinic (Fig. 1). The effect of another such intervention was already discussed in the literature (9).

Despite negative trends, signs of the predicted HIV epidemic among IDUs, as predicted by other authors $(9,10)$, are not seen. Neither local, nor national data support the fears of Hungarian authors of the possible HIV outbreak among IDUs. Collected local data showed that cases were sporadic rather than interconnected (Table 3), while national data displayed stagnation in new HIV cases in the recent years (Table 4).

To sum up, basically negative trends are seen in Hungarian addicted patient care in the last almost three decades. The high drop-out rate strongly suggests that the system is no longer capable of treating and keeping care of the clients. So, a large group of patients may remain without treatment. The HIV epidemic predicted by others, however, has not manifested either locally or nationally as supported by the data. Although the risk of a future HIV epidemic eventually emerging in the next several years does not seem threatening at the moment, the possibility, even though minimal, exists as the rate of untreated drug abusers is high.

\section{Conflict of Interests}

None declared

\section{Acknowledgements}

The author thanks street workers Ms. Virág Kováts and Mr. Roland Gyékiss for the information they provided upon HIV screening among illicit drug users in the 8th District of Budapest. This work was made possible by the financial support of the Theoretical Biology Research Group (Budapest, Hungary). The author also thanks dr. Ágnes Kocsis, psychiatrist (LA, USA) for her critical reading of the manuscript.

\section{REFERENCES}

1. Poznyak V, Rekve D, editors. Global status report on alcohol and health. Geneva: WHO; 2014.

2. United Nations. World drug report 2015. Vienna: United Nations Office on Drugs and Crime; 2015.

3. Kalapos MP. Introduction to addictology. Budapest: Medicina; 2016. (In Hungarian.)

4. Kalapos MP. Introduction to alcohology. Budapest: Medicina; 2007. (In Hungarian.)

5. Mundt AP, Frančišković T, Gurovich I, Heinz A, Ignatyev Y, Ismayilov F, et al. Changes in the provision of institutionalized mental health care in post-communist countries. PLoS One. 2012;7(6):e38490. doi: 10.1371/ journal.pone. 0038490 
6. Vlahov D, Robertson AM, Strathdee SA. Prevention of HIV infection among injection drug users in resource-limited settings. Clin Infect Dis. 2010 May 15;50 Suppl 3(Suppl 3):S114-21.

7. Paraskevis D, Nikolopoulos G, Fotiou A, Tsiara C, Paraskeva D, Sypsa $\mathrm{V}$, et al. Economic recession and emergence of an HIV-1 outbreak among drug injectors in Athens metropolitan area: a longitudinal study. PLoS One. 2013 Nov 12;8(11):e78941. doi: 10.1371/journal.pone.0078941.

8. Nikolopoulos GK, Sypsa V, Bonovas S, Paraskevis D, Malliori-Minerva M, Hatzakis A, et al. Big events in Greece and HIV infection among people who inject drugs. Subst Use Misuse. 2015;50(7):825-38.

9. Rácz J, Gyarmathy VA, Csák R. New cases of HIV among people who inject drugs in Hungary: false alarm or early warning? Int J Drug Policy. 2016 Jan;27:13-6.

10. Gyarmathy VA, Csák R, Bálint K, Bene E, Varga AE, Varga M, et al. A needle in the haystack - the dire straits of needle exchange in Hungary. BMC Public Health. 2016 Feb 16;16:157. doi: 10.1186/s12889-016-28422.

11. Kalapos MP. Addiction therapy. Limits, problems, perspectives. Psychiatr Hung. 2014;29(3):308-27. (In Hungarian.)

12. Molnár G. The homeless health care services, with special respect to their psychological state. In: Glatz F, editor. Living situation, quality of life, dead-ends and ways out. Budapest: Hungarian Academy of Sciences; 2002. p.137-61 (In Hungarian.)
13. Fazel S, Khosla V, Doll H, Geddes J. The prevalence of mental disorders among the homeless in western countries: systematic review and metaregression analysis. PLoS Med. 2008 Dec 2;5(12):e225. doi: 10.1371/ journal.pmed.0050225.

14. Cartwright WS. Cost-benefit analysis of drug treatment services: review of the literature. J Ment Health Policy Econ. 2000 Mar 1;3(1):11-26.

15. Gulácsi L. The concept and measurement of quality in health care. In Gulácsi L, editor. Quality improvement in health care. Budapest: Medicina; 2000. p. 113-42. (In Hungarian.)

16. Taylor PJ, Gunn J. Homicides by people with mental illness: myth and reality. Br J Psychiatry. 1999 Jan;174(1):9-14.

17. Gunn J. Future directions for treatment in forensic psychiatry. Br J Psychiatry. 2000 Apr;176(4):332-8.

18. Salvador-Carulla L. Bridging experience and evidence in mental health care reform. World Psychiatry. 2008;7(2):99-100.

19. Kalapos MP. Penrose's law: methodological challenges and call for data. Int J Law Psychiatry. 2016 Sep-Dec;49(Pt A):1-9.

Received May 17, 2018

Accepted in revised form December 7, 2020 